\title{
RENDIMENTO E COMPOSIÇÃO DAS AGUARDENTES DE CANA, LARANJA E UVA COM UTILIZAÇÃO DE LECITINA NO PROCESSO FERMENTATIVO
}

\author{
Yield and composition of sugar cane, orange and \\ grape spirits using lecithin in the fermentation process
}

Francisco Vicente Gaiotto Cleto ${ }^{1}$, Márcia Justino Rossini Mutton ${ }^{2}$

\begin{abstract}
RESUMO
O presente trabalho foi desenvolvido com o objetivo de avaliar o efeito da adição de lecitina aos mostos de cana, laranja e uva sobre o rendimento e composição das aguardentes. O delineamento empregado para a análise estatística foi o de blocos casualizados, no esquema fatorial $2 \times 3$, empregando-se dois fatores - lecitina e mosto - em dois níveis para lecitina: ausência (índice um) e presença (índice dois); e em três níveis para mosto: cana, laranja e uva. A metodologia empregada foi a recomendada pelo setor aguardenteiro e as análises químicas dos componentes secundários foram realizadas por cromatografia gasosa e espectrofotometria. Pelos resultados, conclui-se que quando se adiciona lecitina aos mostos de cana, laranja e uva, o vinho obtido após a fermentação tem maior concentração de glicerol, e as aguardentes produzidas pela destilação têm maior concentração de isobutanol. Já nos mostos em que foi adicionada a lecitina, o rendimento alcoólico total das aguardentes foi menor do que nos mostos que não a recebeu. Os componentes secundários acetaldeído, acetato de etila e acidez total aumentaram com o aumento da acidez nos vinhos. Por outro lado, o propanol, isobutanol e álcool isoamílico aumentaram com os aumentos dos pH e das concentrações nos mostos, dos aminoácidos treonina, valina e leucina. A concentração do furfural foi maior nas aguardentes provenientes dos mostos de cana e laranja.
\end{abstract}

Termos para indexação: Lecitina, aguardente, componentes secundários, vinho, laranja, uva, cana-de-açúcar.

\begin{abstract}
The present research was carried out to evaluate the effect of lecithin addition into sugar cane, orange and grape musts on the spirits yield and composition. The statistical design was randomized blocks, in $2 \times 3$ factorial array, using two factors: lecithin and must, two levels for lecithin (absence and presence); and three levels for must (sugar cane, orange and grape). The method used in this work is recommended by mills. The measurement of by-products was made through gas chromatography and spectrophotometry. The results showed that the lecithin addition into sugar cane, orange and grape increased the concentration of glycerol in these musts as well as the concentration of butyl alcohol in the spirits, and decreased the total alcoholic yield. Acetaldehyde, ethyl acetate and total acidity increased with the elevation of the acidity. On the other hand, propanol-1, butyl and isoamyl alcohols, increased with the elevation of the $\mathrm{pH}$ of the fermenting musts and the concentration of the amino acids threonine, leucine and valine in the musts. Furfural content was greater in the spirits made from the sugar cane and orange musts.
\end{abstract}

Index terms: Lecithin, spirits, by-products, orange, grape, musts.

(Recebido para publicação em 4 de dezembro de 2002 e aprovado em 7 de maio de 2003)

\section{INTRODUÇÃO}

O Brasil destaca-se na comunidade internacional como grande produtor de matérias-primas vegetais, por apresentar características essencialmente agrícolas. Não obstante, vivencia-se o momento em que é necessário ao país tornar-se grande produtor industrial, agregando valores à produção primária. Segundo estatísticas oficiais, a produção de aguardente no Brasil ultrapassa a marca de 1 bilhão de litros por ano. Entretanto, devido à falta de melhor elaboração do produto e conhecimentos técnico-científicos que possam cooperar para sua melhoria, as receitas obtidas com sua comercialização estão aquém daquelas recebidas por outros fabricantes de destilados, em outras partes do mundo, tais como uísque, rum, tequila, conhaque, vodca, entre outros, que utilizam alta tecnologia.

1. Engenheiro Agrônomo, Ministério da Agricultura, Pecuária e Abastecimento/MAPA.

2. Engenheiro Agrônomo, Faculdade de Ciências Agrárias e Veterinária/UNESP, Campus de Jaboticabal, Departamento de Tecnologia, Via de Acesso Prof. Paulo Donato Castellane, s/n, 14.884-900 - Jaboticabal, SP, Fone/fax: (016) 3209-2675/2676/2677. mjrmut@fcav.unesp.br. 
Muitos produtores de aguardente utilizam nos processos fermentativos coadjuvantes como o fubá, farelo de arroz e suco de limão, entre outros, objetivando a melhoria do destilado final (MAIA e NELSON, 1994), sem conhecerem as verdadeiras funções desses suplementos. A lecitina é o subproduto da fabricação do óleo de soja que contém em sua composição fosfatídeos e ácidos graxos, que são utilizados pelas leveduras no processo fermentativo. Não obstante, seu emprego requer maiores estudos.

De acordo com o Ministério da Agricultura, Pecuária e Abastecimento, "Brandy" ou aguardente de fruta é a bebida com graduação alcoólica de 36 a $54 \%$ em volume a $20^{\circ} \mathrm{C}$, obtida do destilado alcoólico simples de fruta ou do mosto fermentado de fruta (BRASIL, 1997a). Aguardente de cana é a bebida com graduação alcoólica de 38 a $54 \%$ em volume a $20^{\circ} \mathrm{C}$, obtida do destilado alcoólico simples de cana-de-açúcar ou pela destilação do mosto fermentado de cana-de-açúcar, podendo ser adicionada de açúcares até $6 \mathrm{~g} / \mathrm{L}$ (BRASIL, 1997b). A fermentação dos mostos de cana-de-açúcar, laranja e uva produzem, além do álcool etílico, seu principal produto, vários outros componentes chamados secundários, como os aldeídos, metanol, álcoois superiores, ácidos, ésteres, cetonas, fenóis, mercaptanas, entre outros (MAIA, 1994). Apesar da pequena quantidade dessas substâncias, em relação à água e ao etanol, elas são determinantes na caracterização do "flavour", que é definido como sendo a mistura das sensações de aroma e sabor (STEVENS, 1960) e tem grande influência sobre a qualidade das aguardentes.

Considerando-se a importância do rendimento alcoólico e dos componentes secundários das aguardentes envolvendo a utilização de lecitina no processo fermentativo, destinado a produção de bebidas destiladas, com o presente estudo objetivou-se avaliar o efeito da lecitina em mostos de cana, laranja e uva, e seus reflexos sobre o rendimento e a composição das aguardentes obtidas.

\section{MATERIAL E MÉTODOS}

Os mostos utilizados foram obtidos de xarope de cana-de-açúcar e de sucos concentrados de laranja e de uva, obtidos em usina e fábricas de sucos concentrados da região de Jaboticabal - SP, na safra 1999/2000. As leveduras utilizadas na fermentação foram células de Saccharomyces cereviseae.
Para o preparo dos pés-de-cuba, foram utilizadas $100 \mathrm{~g}$ de fermento prensado, dissolvido em água, adicionando-se em seguida $2,5 \mathrm{~g}$ de lecitina/L de mosto.

Após o preparo dos mostos $(3100 \mathrm{~mL})$ e a adição do inóculo ou pé-de-cuba $(800 \mathrm{~mL})$, iniciou-se a fermentação, a $32^{\circ} \mathrm{C}$, que foi conduzida em batelada, com duração de 28 horas. No final da fase fermentativa, foram realizadas análises de brix, açúcares redutores residuais totais, acidez, $\mathrm{pH}$, glicerol e contagens de bactérias e leveduras, segundo Copersucar (1987).

Concluída a etapa fermentativa, e tendo decantado todo o fermento, o vinho sobrenadante foi coletado para a destilação em um minialambique de vidro, com dispositivo de cobre e capacidade para 3 litros (Figura 1).

O destilado produzido foi coletado, sem a separação de "cauda" e "cabeça", para permitir a verificação dos reflexos da adição de lecitina e das diferenças nos mostos no processo fermentativo. Os componentes secundários presentes foram avaliados por cromatografia gasosa, empregando-se coluna Megabor DB Wax, temperaturas mínima de $20^{\circ} \mathrm{C}$ e máxima de $230-240^{\circ} \mathrm{C}$ (MONICK, 1986).

O delineamento empregado para análise estatística foi o de Blocos Casualizados, segundo Banzatto e Kronka (1992), no esquema fatorial $2 \times 3$, empregando-se 2 fatores: lecitina e mostos de cana, laranja e uva, sendo 2 níveis para lecitina: ausência (índice um) e presença (índice dois); e 3 níveis para mosto (cana, laranja e uva). O experimento, com seis repetições, foi realizado durante a safra 1999/2000. Da combinação entre os fatores, obtiveram-se os seguintes tratamentos: $\mathrm{L}_{1} \mathrm{M}_{1}$ (ausência de lecitina e mosto de cana); $\mathrm{L}_{1} \mathrm{M}_{2}$ (ausência de lecitina e mosto de laranja); $\mathrm{L}_{1} \mathrm{M}_{3}$ (ausência de lecitina e mosto de uva); $\mathrm{L}_{2} \mathrm{M}_{1}$ (presença de lecitina e mosto de cana); $\mathrm{L}_{2} \mathrm{M}_{2}$ (presença de lecitina e mosto de laranja); $\mathrm{L}_{2} \mathrm{M}_{3}$ (presença de lecitina e mosto de uva).

\section{RESULTADOS E DISCUSSÃO}

Os valores das análises físico-químicas e microbiológicas dos mostos estão apresentados nos Quadros 1 e 2.

As leveduras utilizadas na fermentação foram células de Saccharomyces cerevisiae, cujas características químicas e microbiológicas estão apresentadas no Quadro 3. 


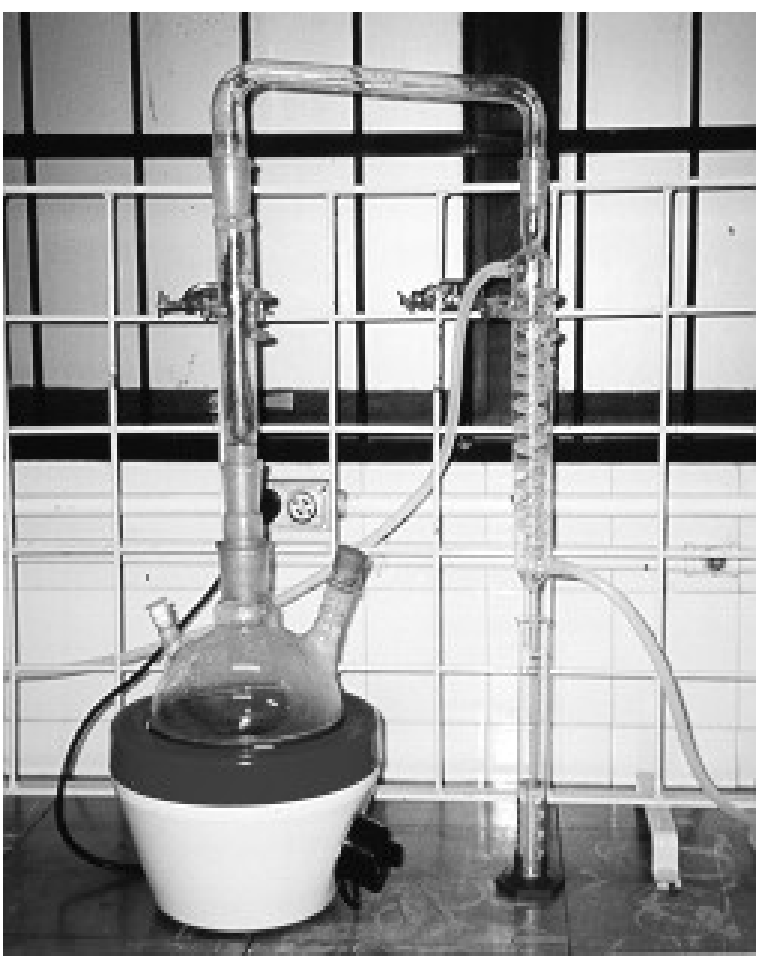

FIGURA 1 - Minialambique de vidro empregado na destilação do vinho.

QUADRO 1 - Quantidades de alguns aminoácidos nos mostos de cana, laranja e uva.

\begin{tabular}{|c|c|c|c|}
\hline Aminoácidos & Cana $(\mathbf{m g} / \mathbf{L})$ & Laranja $(\mathbf{m g} / \mathbf{L})$ & Uva (mg/L) \\
\hline Treonina & 1213,0 & 42,6 & 25,2 \\
\hline Leucina & 84,0 & 15,2 & 10,6 \\
\hline Valina & 229,0 & 50,5 & 42,6 \\
\hline TOTAL & 1556,0 & 108,3 & 48,4 \\
\hline
\end{tabular}

Fonte: Laranja - Coinbra-Frutesp S.A. - Bebedouro, SP; Uva - Embrapa - Bento Gonçalves, RS; Cana Ital - Campinas, SP.

QUADRO 2 - Resultados médios das características químicas e microbiológicas dos mostos.

\begin{tabular}{|c|c|c|c|c|c|c|c|}
\hline & $\begin{array}{c}\text { Brix } \\
\%\end{array}$ & $\underset{\%}{\mathrm{ART}}$ & pH & $\begin{array}{c}\text { Acidez Total } \\
\left(\mathrm{g} \mathrm{H}_{2} \mathrm{SO}_{4} / \mathrm{L}\right)\end{array}$ & $\begin{array}{c}\text { MCF } \\
\left(\mathrm{UFC} \cdot 10^{3} / \mathrm{mL}\right)\end{array}$ & $\begin{array}{c}\text { PCA } \\
\left(\text { UFC } .10^{4} / \mathrm{mL}\right)\end{array}$ & $\begin{array}{c}\text { MRS } \\
\left(\mathrm{UFC} .10^{4} / \mathrm{mL}\right)\end{array}$ \\
\hline Cana Média & 15,4 & 14,0 & 6,7 & 0,6 & 5,5 & 1,5 & 7,6 \\
\hline Laranja Média & 17,9 & 13,9 & 4,0 & 7,7 & 2,2 & 0,4 & 1,9 \\
\hline Uva Média & 15,4 & 13,8 & 3,1 & 4,6 & 0,3 & 0,04 & 0,3 \\
\hline
\end{tabular}

MCF = Contagem de Leveduras; PCA = Contagem de Microrganismos Totais; MRS = Contagem de bactérias (lactobacilos).

Ciênc. agrotec., Lavras, v. 28, n. 3, p. 577-584, maio/jun., 2004 
QUADRO 3 - Resultados médios das análises químicas e microbiológicas do fermento.

\begin{tabular}{|c|c|c|c|c|c|c|}
\hline Fermento & $\begin{array}{c}\text { Acidez Total } \\
\left(\mathbf{g ~ H}_{\mathbf{2}} \mathbf{S O}_{\mathbf{4}} / \mathbf{L}\right)\end{array}$ & $\mathbf{p H}$ & $\begin{array}{c}\text { Viabilidade } \\
(\mathbf{\%})\end{array}$ & $\begin{array}{c}\mathbf{M C F} \\
\left(\mathbf{U F C} \times \mathbf{1 0}^{\mathbf{1 0}} / \mathbf{m L}\right)\end{array}$ & $\begin{array}{c}\text { PCA } \\
\left.\mathbf{x} \mathbf{1 0}^{\mathbf{1 0}} / \mathbf{m L}\right)\end{array}$ & $\begin{array}{c}\text { (UFC } \\
\mathbf{x ~ 1 0} / \mathbf{m L})\end{array}$ \\
\hline Médias & 0.72 & 4,43 & 95,7 & 6,4 & 6,5 & 6,0 \\
\hline
\end{tabular}

MCF = Contagem de Leveduras; PCA = Contagem de Microrganismos Totais; MRS = Contagem de bactérias (lactobacilos)

Pelos resultados de porcentagem alcoólica das aguardentes, verificou-se que não houve diferença significativa entre médias em relação aos fatores lecitina e mosto. Nas parcelas em que foi adicionada lecitina ao mosto, essas médias foram da ordem de $40,7 \%$ em volume, enquanto na testemunha, foi de $41,5 \%$. As porcentagens alcoólicas médias das aguardentes obtidas foram de $41,5 \%$ em volume; $41,2 \%$ e $40,5 \%$, respectivamente para uva, cana e laranja. Verificou-se que os fosfatídeos e ácidos graxos, existentes na lecitina, e as condições diferentes de acidez sulfúrica e $\mathrm{pH}$ dos mostos utilizados não influenciaram a via fermentativa da levedura.

Pelos resultados de rendimento alcoólico total (fermentação e destilação), constataram-se diferenças significativas entre os tratamentos com lecitina e mosto (Tabela 1). A média entre as parcelas que tiveram adição de lecitina foi $65,0 \%$ e a das sem lecitina, $66,2 \%$, inferindo-se que a produção de etanol foi prejudicada pela adição desse componente.

As médias dos rendimentos alcoólicos das aguardentes obtidas dos mostos de uva, cana e laranja (Tabela 1) foram, respectivamente, 66,8\%; 65,3\%; $64,6 \%$. Houve diferença entre as médias de uva e laranja $(66,8 \%$ e $64,6 \%)$. O melhor rendimento foi o obtido para o vinho proveniente do mosto de uva, que apresentou as menores contagens bacterianas, e os menores valores de $\mathrm{pH}$, indicando que os contaminantes encontraram condições adversas no meio e, como conseqüência, utilizaram menores quantidades de açúcares do mosto, resultando em melhores condições para o desenvolvimento das leveduras.

A adição da lecitina ao mosto deve ter estimulado a multiplicação das leveduras, através da via aeróbica (ciclo do ácido cítrico), em detrimento da via fermentativa. Os açúcares dissolvidos foram utili- zados pelas leveduras para a multiplicação celular, por meio da respiração, ficando prejudicada a produção de etanol pela via anaeróbica. Resultados semelhantes foram obtidos por Duarte (1996), que constataram o efeito favorável da lecitina no desempenho fermentativo e no estímulo ao brotamento nas leveduras.

Quanto aos componentes secundários, as médias apresentadas na Tabela 1 mostraram não haver diferenças significativas em relação ao fator lecitina, o que não ocorreu com os componentes glicerol e isobutanol.

Em relação ao fator mosto, houve diferenças entre todas as médias analisadas.

Para o glicerol, observaram-se diferenças entre os fatores lecitina e mosto, o que permitiu constatar que quando se adiciona lecitina no processo, os vinhos obtidos apresentaram quantidades maiores desse composto. A média de glicerol para os tratamentos com lecitina foi de $10,8 \mathrm{mg} / 100 \mathrm{~mL}$ de álcool anidro, ou seja, 4,8\% maior do que a dos sem lecitina, que foi de $10,3 \mathrm{mg} / 100 \mathrm{~mL}$ de a.a.

$\mathrm{O}$ esquema fatorial estatístico permite analisar separadamente os fatores mosto e lecitina. Quando se analisa o fator lecitina, o fator mosto permanece constante, e vice-versa. $\mathrm{O}$ aumento do glicerol nas parcelas que foi adicionada à lecitina se deve à hidrólise das moléculas dos fosfatídeos (fosfatidil colina, etanolamina e inositol) encontrados na lecitina, em conseqüência do $\mathrm{pH}$ ácido do meio fermentativo. Verifica-se que nos tratamentos em que foi adicionada lecitina, houve aumento do glicerol, devido à hidrólise dos fosfatídeos, além das quantidades produzidas de glicerol, pelo metabolismo da levedura, Connstein e Ludecke, citados por Amorim (1977). 


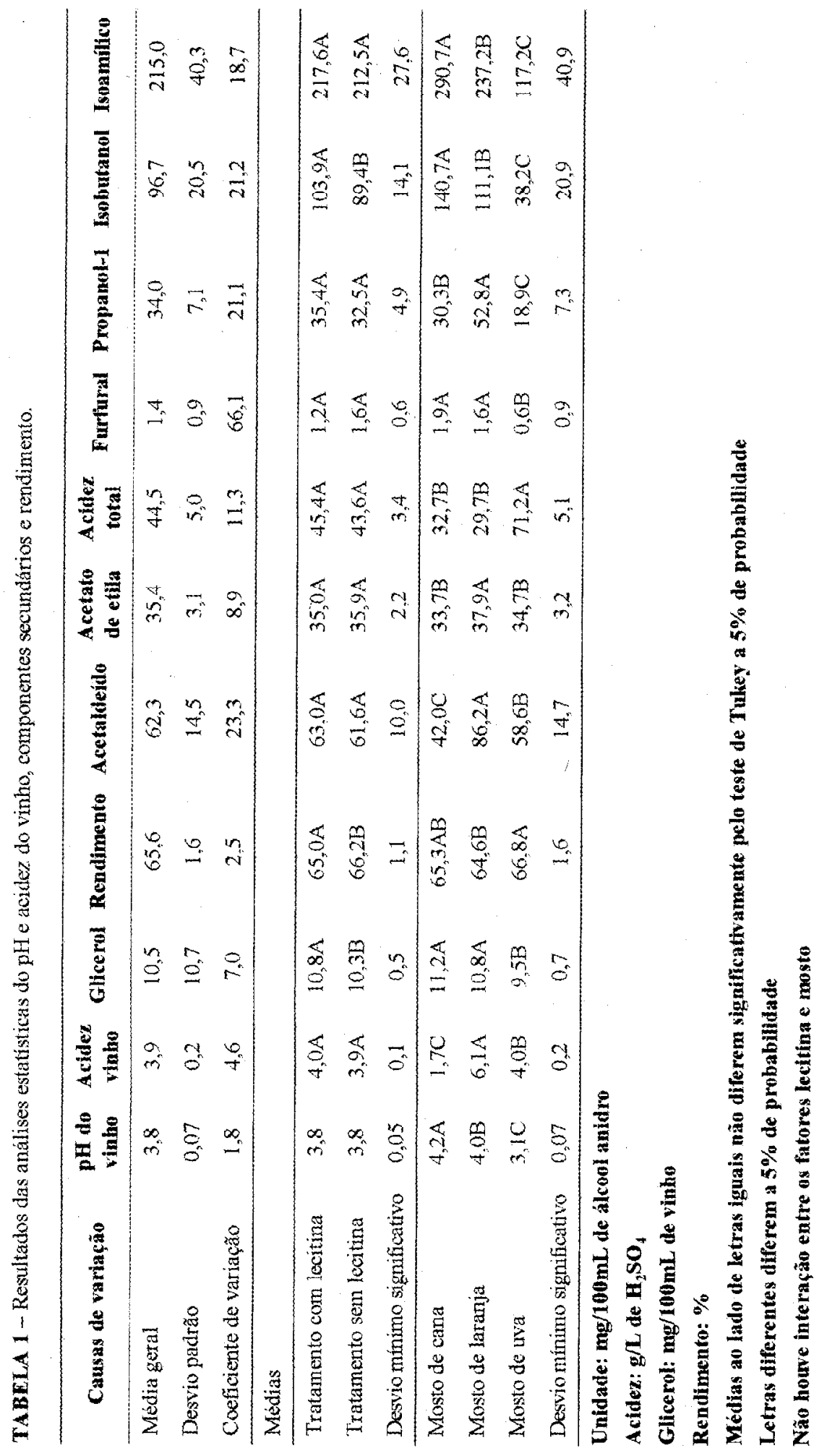

Ciênc. agrotec., Lavras, v. 28, n. 3, p. 577-584, maio/jun., 2004 
As concentrações médias de glicerol nos vinhos, provenientes dos três mostos utilizados, foram maiores para os mostos com $\mathrm{pH}$ maiores: cana (pH 6,7) e laranja (pH 4,0), sendo 11,2 mg/100 $\mathrm{mL}$ de a.a. e 10,8 $\mathrm{mg} / 100 \mathrm{~mL}$ de a.a., respectivamente maiores do que as obtidas para o mosto de uva, que apresentou o menor pH $(3,1)$ e 9,5 mg/100mL de a.a. de glicerol no vinho. Connstein e Ludecke, citados por Amorim (1977), concluíram que o aumento do $\mathrm{pH}$ do meio fermentativo provocava o aumento na produção de glicerol, que é formado pelas leveduras através da via glicolítica. $\mathrm{O} \mathrm{pH}$ alcalino libera o grupo $\mathrm{OH}^{--}$, que reage com o hidreto, necessário para a redução do aldeído a álcool, na reação de óxido-redução, catalisada pela desidrogenase alcoólica. Dessa maneira, o equilíbrio inverso da reação é favorecido (AMORIM, 1977).

Quanto ao acetaldeído obtido nas aguardentes, as diferenças foram significativas para todas as médias analisadas (fator mosto), sendo $86,2 \mathrm{mg} / 100 \mathrm{~mL}$ de a.a. para o acetaldeído proveniente do mosto fermentado de laranja e 58,6 mg/100mL de a.a. para o de uva, maiores do que o de cana, que foi de $42,0 \mathrm{mg} / 100 \mathrm{~mL}$ de a.a. de acetaldeído.

Nesse caso, a matéria-prima influiu sobre a composição da aguardente obtida. Quanto maior a acidez do vinho de laranja, uva e cana, que foi respectivamente de 6,1 g de $\mathrm{H}_{2} \mathrm{SO}_{4} / \mathrm{L}$; uva, 4,0; e cana, 1,7 (Tabela 1), maior a quantidade de acetaldeído nas aguardentes. Segundo Suomalainen e Lehtonen (1979), os aldeídos são de suma importância como compostos aromáticos, devido aos seus baixos valores sensoriais. A baixa acidez dos mostos de laranja e uva provoca a diminuição do $\mathrm{pH}$ do meio, liberando o íon $\mathrm{H}+$, que reage com o íon $\mathrm{OH}^{+}$, oxidando o álcool etílico a acetaldeído.

Para o acetato de etila, observaram-se diferenças significativas entre as duas médias analisadas. Elas foram não-significativas, para uva e cana, ou seja, 34,7 $\mathrm{mg} / 100 \mathrm{~mL}$ de a.a. e $33,7 \mathrm{mg} / 100 \mathrm{~mL}$ de a.a., menores do que para a laranja $(37,9 \mathrm{mg} / 100 \mathrm{~mL}$ de a.a. $)$, que se apresentou significativa em relação a elas. Verificouse que quanto maior a acidez do mosto (Quadro 2) e maior a acidez do vinho (Tabela 1), maior a concentração de acetato de etila na aguardente obtida. Trabalho de Cleto e Mutton (1997) corrobora essas informações. A formação dos ésteres realiza-se pela reação da acetil-CoA, com um álcool, originando a CoA e um éster Nordström (1964). A maior acidez do mosto de laranja pode ter incrementado a via metabólica da produção dos ésteres.

$\mathrm{Na}$ acidez total, observaram-se diferenças significativas para as duas médias analisadas. Elas foram para cana e laranja, respectivamente, $32,7 \mathrm{mg} / 100 \mathrm{~mL}$ de a.a. e $29,7 \mathrm{mg} / 100 \mathrm{~mL}$ de a.a., não-significativas, menores do que para uva $(71,2 \mathrm{mg} / 100 \mathrm{~mL}$ de a.a.) , que foi significativa em relação às outras duas. Considerandose a relação ao $\mathrm{pH}$ do mosto (Quadro 2) e a concentração de ácidos nas aguardentes, observou-se comportamento inverso, ou seja, o mosto com menor $\mathrm{pH}$ (uva) apresentou maior concentração de ácidos. O menor valor de $\mathrm{pH}$ pode ter incrementado as vias metabólicas da levedura, que produzem os ácidos graxos de cadeia curta. Zee (1984), analisando "brandies" (destilados de uva), concluíram que o aumento da acidez reduz a apreciação sensorial dos destilados.

O furfural não é formado durante a fermentação alcoólica. Sua presença, no caso da cana, foi constatada no destilado devido à desidratação parcial de pequenas quantidades de pentoses provenientes de cana queimada na colheita (MAIA, 1994). Diferenças significativas para as duas médias analisadas foram observadas para cana e laranja, respectivamente, $1,9 \mathrm{mg} / 100 \mathrm{~mL}$ de a.a. e $1,6 \mathrm{mg} / 100 \mathrm{~mL}$ de a.a., maiores que as de uva $(0,6$ $\mathrm{mg} / 100 \mathrm{~mL}$ de a.a.).

Para o propanol-1, pelos números, infere-se que há diferenças significativas para todas as médias analisadas. Elas foram para laranja e cana, respectivamente, $52,8 \mathrm{mg} / 100 \mathrm{~mL}$ de a.a. e $30,3 \mathrm{mg} / 100 \mathrm{~mL}$ de a.a., maiores do que para uva $(18,9 \mathrm{mg} / 100 \mathrm{~mL}$ de a.a.). Rankine (1967) verificou que o aumento do $\mathrm{pH}$ de 3,0 para 4,2 no processo fermentativo, utilizandose quatro leveduras, produziu $28 \%$ a mais de álcoois isoamílico e amílico ativo, $85 \%$ a mais de isobutanol e $11 \%$ a mais de propanol. Neste estudo, verificou-se que o $\mathrm{pH}$ dos vinhos de uva, laranja e cana foram respectivamente, 3,1; 4,0; 4,2 (Tabela 1). Observouse que as concentrações do propanol, isobutanol e isoamílico nas aguardentes obtidas aumentaram à medida que os pHs dos vinhos foram aumentando, confirmando os resultados obtidos por Rankine (1967).

Segundo Reazin (1973), os álcoois propílico, damílico e isoamílico são produzidos, em parte, pelo me-

Ciênc. agrotec., Lavras, v. 28, n. 3, p. 577-584, maio/jun., 2004 
tabolismo do aminoácido treonina, pelas leveduras. Conforme os dados do Quadro 1, a maior quantidade da treonina nos mostos de cana e laranja pode ter promovido maior atividade da via metabólica relativa à formação do ácido $\alpha$ cetobutírico e, posteriormente, do álcool propílico.

Pelas análises estatísticas para o isobutanol, constatou-se que houve diferença significativa quando se analisaram as médias dos fatores lecitina e mosto. Com os resultados pôde-se verificar que quando se adiciona lecitina nos mostos, as aguardentes obtidas apresentam quantidades maiores de isobutanol. A média para os tratamentos nos quais foi adicionada lecitina foi $103,9 \mathrm{mg} / 100 \mathrm{~mL}$ de a.a., maior do que a que não foi adicionada $(89,4 \mathrm{mg} / 100 \mathrm{~mL}$ de a.a.). Esses resultados foram corroborados por Gutierrez (1990) que, utilizando os ácidos palmítico, olêico e linolêico, trabalhando com $S$. cereviseae em fermentações com mosto a concentrações de 14 a $16 \%$ de sacarose, observou maior produção de álcoois superiores (propílico, isobutílico e isoamílico). Na lecitina, os ácidos olêico e linolêico encontram-se em altas concentrações. Quanto ao fator mosto, observaram-se diferenças significativas para todas as médias analisadas. Elas foram para cana e laranja, respectivamente, $140,7 \mathrm{mg} / 100 \mathrm{~mL}$ de a.a. e 111,1 $\mathrm{mg} / 100 \mathrm{~mL}$ de a.a., maiores do que para uva $(38,2$ $\mathrm{mg} / 100 \mathrm{~mL}$ de a.a.).

Engan (1970), estudando os álcoois superiores em cerveja, constatou que a adição da valina no meio fermentativo aumentava a concentração do isobutanol, que é formado do ceto ácido, correspondente a esse aminoácido, obtido de sua descarboxilação e posterior redução. O ceto ácido pode ser derivado da valina, existente no meio fermentativo, ou sintetizado de outras fontes de carbono pela mesma via que o correspondente aminoácido (esquema EhrlichNeubauer e Fromherz), Guymon (1961). Conforme dados do Quadro 1, a maior quantidade de valina nos mostos de laranja e cana pode ter promovido maior atividade das vias metabólicas da levedura, relativas à valina, resultando no aumento da concentração do isobutiraldeído e, posteriormente, do isobutanol. Resultados semelhantes foram obtidos por Cleto e Mutton (1997) e Cleto (1997), trabalhando com a adição de fubá (rico em valina), no processo fermentativo.
Para o álcool isoamílico, observaram-se diferenças em todas as médias analisadas. Elas foram para cana e laranja, respectivamente, $290,7 \mathrm{mg} / 100 \mathrm{~mL}$ de a.a. e $237,2 \mathrm{mg} / 100 \mathrm{~mL}$ de a.a., maiores do que para uva (117,2 mg/100mL de a.a.).

Segundo Engan (1970), Guymon (1961), Maia (1994) e Cleto (1997), a concentração do álcool isoamílico é incrementada pela conversão do aminoácido leucina, pela levedura, conforme o esquema de EhrlichNeubauer e Fromherz, Guymon (1961), na fermentação alcoólica.

\section{CONCLUSÕES}

A utilização da lecitina no processo fermentativo diminuiu o rendimento alcoólico, proporcionando o aumento das concentrações de glicerol no vinho e do álcool isoamílico nas aguardentes obtidas. As matériasprimas utilizadas (mostos de cana, laranja e uva) influenciaram o rendimento alcoólico e a concentração dos componentes secundários.

\section{REFERÊNCIAS BIBLIOGRÁFICAS}

AMORIM, H. V. Introdução à bioquímica da fermentação alcoólica. Araras: Planalsucar, 1977. 95 p.

BANZATTO, D. A.; KRONKA, S. N. Experimentação agrícola. 2. ed. Jaboticabal: FUNEP, 1992. 247 p.

BRASIL. Decreto n. 2.314, de 4 de set. de 1997. Dispõe sobre a padronização, a classificação, o registro, a inspeção, a produção e a fiscalização de bebidas. Brasília, cap. IV, Seção IV, Art. 96a. 1997a.

BRASIL. Decreto n. 2.314 de 4 de set. de 1997. Dispõe sobre a padronização, a classificação, o registro, a inspeção, a produção e a fiscalização de bebidas. Brasília, cap. IV, Seção IV, Art. 91b. 1997b.

CLETO, F. V. G. Influência da adição do ácido sulfúrico e fubá de milho no processo fermentativo, rendimento e composição da aguardente. 1997. $109 \mathrm{f}$. Dissertação (Mestrado em Produção Vegetal) - Universidade Estadual Paulista, Jaboticabal, 1997.

CLETO, F. V. G.; MUTTON, M. J. R. Rendimento e qualidade da aguardente de cana produzida utilizando fermento tratado com ácido e fubá de milho. Stab Açúcar, Álcool e Subprodutos, [S.1.], v. 16, n. 2, p. 38-40, 1997. 
COPERSUCAR. Fermentação. Piracicaba: Centro de Tecnologia Copersucar, 1987. 434 p.

DUARTE, M. C. T. Effect of lecithin and of soy oil on the fermentative performance of Saccharomyces uvarum IZ 1904. Journal of the Brazilian Society for Microbiology, São Paulo, v. 27, p. 255-262, 1996.

ENGAN, S. The influence of some amino acids on the formation of higher aliphatic alcohol and esters Journal of the Institute of Brewing, Brewing, v. 76, p. 254-256, 1970.

GUTIERREZ, L. E. Capacidade fermentativa de Saccharomyces cerevisiae enriquecida de ácidos graxos. Anais ESALQ, Piracicaba, v. 47, parte 2, p. 575-595, 1990.

GUYMON, J. F. The formation of n-propanol by Saccharomyces cerevisiae. Archives Biochemistry Biophysics, New York, v. 95, p. 163-168, 1961.

MAIA, A. B. R. A. Componentes secundários da aguardente. Stab Açúcar, Álcool e Subprodutos, [S.1.], v. 12, n. 6, p. 29-33, 1994.

MAIA, A. B. R. A.; NELSON, D. Comparative study of soy and corn flours on the of alcoholic fermentation in successive batches. Journal Chemical Technology Biotechnology, v. 59, p. 171-179, 1994.
MONICK, J. A. Alcohol: their chemitry, properties and manufature. New York: Renhold Book, 1986. 576 p.

NORDSTRÖM, K. Formation of esters from acids by brewer's yeast: II. formation from lower fatty acids. Journal of the Institute of Brewing, Brewing, v. 70, p. 42-55, 1964.

RANKINE, B. C. Formation of higher alcohols by wine yeasts. Journal Science Food Agricultural, London, v. 18, p. 583-589, 1967

REAZIN, G. Production of higher alcohols from threonine and isoleucine in alcoholic fermentations of different types of grain mash. Journal of Agricultural and Food Chemistry, Easton, v. 21, n. 1, p. 50-54, 1973.

STEVENS, R. Beer Flavour: I. volatile products of fermentation: a review. Journal of the Institute of Brewing, Brewing, v. 66, p. 456-471, 1960.

SUOMALAINEN, H.; LEHTONEN, M. The production of aroma compounds by yeast. Journal of the Institute of Brewing, Brewing, v. 85, p. 149$156,1979$.

ZEE, J. Comparative composition of fusel oils in brandies mode from six grape varieties and their relationship with sensory analysis. Lebensmittel Wissenschaft und Technologie, London, p. 54-59, 1984. 